\title{
Transparency, Control and Power in Legal Semiotics: Contexts and Issues
}

\author{
Vijay Bhatia $\cdot$ Christoph Hafner $\cdot$ Lindsay Miller
}

Published online: 8 October 2010

(C) Springer Science+Business Media B.V. 2010

Legal discourse is different from most other professional discourses, in that the nature and context of its interpretation, whether spoken or written, is very often different from those of other discourse contexts. Whereas in most professional and disciplinary contexts interpretation of discourse is largely hearer or reader based, in that there is some freedom for variable interpretations, of course, with some relevance to the context in which it is being done, interpretation of legal discourse is most often based on its relevance and hence application to critical moments of application in specialized 'sites of engagement' ([1], p. 27) and is often irrespective of the participants involved and still every effort is made to ensure consistency of interpretation. It is particularly so in the case of legislative writing, which is drafted to correct a specific social mischief and hence invariably interpreted in the context of relevant descriptions of such instances of cases, often known as the material facts of the case to which specific legislative statements are applicable. The important implication of these factors is that legal discourse is rarely, if ever, interpreted in vacuum and is almost always interpreted in the context of real life events. Interestingly enough, this does not mean that every time it is interpreted in the context of a set of circumstances in real life, it is interpreted differently; contrary to that, it is most often interpreted consistently and every time a specific interpretation is taken, it achieves the force of law, that is, it becomes a precedent for other decisions in a similar set of descriptions of cases. Underlying this consistency of interpretation is the issue of the nature and extent of detailed specification (under or over specification) which is further related to the issues of transparency, power, and control in specific socio-political contexts, which have important implications for the interpretation of legal discourse in a range of socio-political and other public domains.

We would like to reiterate that although clarity, precision, unambiguity, and all-inclusiveness are the four key aspects of the construction and interpretation of

V. Bhatia $(\bowtie) \cdot$ C. Hafner · L. Miller

Department of English, City University of Hong Kong, Hong Kong, China

e-mail: enbhatia@cityu.edu.hk 
intentions in legal discourse, all-inclusiveness plays the most significant role in the specification of legal scope, which in turn has implications for accessibility and transparency in the expression of rights and obligations, permissions and prohibitions. It is also obvious that transparency, or lack of it, is strategically used in different legal systems, institutions, and contexts in different ways to assign power and control to different players who have specific roles in the construction and interpretation of law. Depending on the institutional roles and the privileges available to institutional players, for instance, the legislature, the judiciary, or the bureaucracy, invariably show preference or dispreference for greater transparency in legal expressions. It is interesting to note that any discussion of the nature and function of detailed specification, or lack of it, has to be discussed in the wider context of a wider socio-political context in which legal discourse is written and interpreted.

Another important factor in present-day contexts is that although law has traditionally been considered jurisdictional in nature, because of the recent globalisation of trade, commerce and industrial practices, it is increasingly being constructed, interpreted, used and exploited in settings across jurisdictional boundaries. Sometimes it is done because of other socio-political developments, such as the return of the sovereignty of Hong Kong to the People's Republic of China (PRC), and the subsequent establishment of the Hong Kong Special Administrative Region (HKSAR) within the PRC. A similar phenomenon in some respects is seen in Europe as a result of the establishment of the European Union. Similarly, the perception that legal discourse is impersonal and highly formal, and that differences in linguistic, socio-political, economic, and cultural factors across national and ideological boundaries will have no significant influence on its construction and interpretation no longer seems to be entirely valid. Moreover, with the increasing dismantling of international trade barriers as a result of international trade agreements and treaties, legal discourse is often being constructed and interpreted across geographical and socio-political borders in different ways, hence general assumptions about meanings cannot be taken for granted in these contexts.

The overall aim of this special issue is to identify a range of contexts and reflect on the growing importance of socio-legal concepts such as Transparency, Control and Power, which have assumed increasing importance in the present-day sociopolitical domains. The value of these concepts has long been considered important in establishing the social order in which the individual rights and privileges, responsibilities and obligations, liberties and constraints on liberties of its citizens are negotiated and maintained. It is necessary for every State to ensure simultaneously and paradoxically a high level of individual freedom and an order in which such freedom is made possible and guaranteed.

The issues of Transparency, Control and Power were the central focus of the 8th International Roundtable for the Semiotics of Law, which brought together academics, scholars and practitioners from a range of disciplines such as law, public and social administration, linguistics and discourse analysis, and semiotics from more than 20 countries to reflect on the growing importance of these concepts and to identify the contexts in which these concepts assume crucial importance in the international community, and how these concerns and ideas have been examined, 
used and interpreted in a range of national and international contexts. Participants explored these issues from a range of overlapping concerns and perspectives, such as semiotic, rhetorical, pragmatic, sociolinguistic, psychological, philosophical, and visual in diverse socio-political, administrative, institutional, as well as legal contexts.

This special issue presents a selection of some of the papers from the 8th Roundtable for the Semiotics of Law, which examine the ways in which 'actors' in our society, which may include legislators, politicians, activists, graffiti artists, photographers, etc. have provoked public discourses to confront the issues of Transparency, Control and Power. The selection has been made keeping in mind a variety of different contexts in which these concepts give rise to some of the issues considered important in the present socio-political order and to provide an opportunity for a general discussion of issues in the semiotics of law as well as open discussions to increase our understanding of the broader context of law and language.

This special issue examines a number of contexts illustrating variations in the specification of legal scope from different socio-political and public domain to identify and discuss issues of transparency, control and power to highlight that while over-specification of information leads to problems of accessibility of discourse (of which legislative statements are prime examples), under specification of information leads to lack of transparency leaving authoritative interpretation to the decision makers, who may be members of the judiciary, bureaucrats, who otherwise are only responsible for carrying out the decisions of the judiciary, people having institutional authority, as is typically done in university and other corporate bodies in the process of appointment and promotion, which clearly indicates that lack of adequate specification leads to lack of transparency and obfuscation and hence can serve as an instrument of institutional empowerment. On the other hand, freedom of interpretation can be viewed as a source of socio-political power and control. However, these opposing tendencies and preferences often lead to various kinds of tension across socio-political and institutional players, such as the bureaucracy, judiciary, legislature, public bodies, non-governmental organisations, media and political players, to name only a few.

The selected papers for this special issue identify and discuss a variety of issues in the context of Transparency, Control and Power. The first paper, by Stephen Bremner, examines the discourse of staff appraisal in higher education contexts. He notes that university education has undergone a gradual transformation in recent times, with universities being increasingly treated more like corporate enterprise than institutions of learning. His study of higher education staff appraisal processes shows how power and control is vested in decision-makers who have the ultimate power to interpret policies, rules and procedures which are often framed in vague and unspecified terms. Bremner argues for greater transparency in the staff appraisal process, with a greater emphasis on staff development as opposed to evaluation.

Joseph Cheng's contribution examines the way that ordinary Hong Kong people perceive the concepts of power, transparency and control. The paper traces political developments in the government of Hong Kong, emphasizing the powerful role of the executive both under British colonial rule and as a Special Administrative Region of the People's Republic of China. It is argued that, in the absence of a 
satisfactory form of democracy, governments must turn to ideology in order to legitimate their power. The analysis illustrates and critiques the way in which Hong Kong people have accommodated to a lack of political power by seeking to control the economic aspects of their lives.

Maurizio Gotti's paper investigates the way in which arbitrators exercise power and control in the context of International Commercial Arbitration proceedings. The study shows how vagueness and indeterminacy in the rules regulating such proceedings allow arbitrators to exercise control, especially over procedural aspects. In addition, an analysis of the spoken interaction of arbitration proceedings demonstrates the arbitrator's power to guide and regulate the contributions of other participants.

Dennis Kurzon's contribution looks at the issue of "moments of silence" in the educational context in the USA. He illustrates how the Courts in the USA have been inconsistent in making decisions regarding whether or not schools can use the moment of silent for religious purposes, which, he claims, may indicate a lack of transparency not only in the interpretation of the relevant phrase in the Constitution but also in the judicial interpretation of the "three-pronged test" with regard to "excessive entanglement" as laid out in Lemon v. Kurtzman of 1971. In his well thought out paper, Kurzon argues that the moment of silence is only long enough for certain faiths to be able to recite a simple prayer, and in a multi-cultural context of many US schools nowadays this causes concern to many parents who claim the educational system is biased in favour of the Christian faith.

Jacque De Ville's paper focuses specifically on a reading of Michel Foucault's lectures from 1975 to 1976 at the College de France. With reference to Foucault's notion of play de Ville deconstructs these lectures to illustrate how we can view law and power. In his analysis, de Ville points out that Foucault constantly refers to the tensions between freedom and order and forces us to consider the struggles we have against disciplinary power in society.

In the last paper of this special edition of The International Journal for the Semiotics of Law Ann Wagner discusses the role visuals play in French urban space. In her paper Wagner states that modern societies have developed complex nonverbal ways of dealing with individuals. By way of graphic examples she illustrates how "urban space management can be analyzed and interpreted under the nature of shape, aesthetics, and ideology." In the process of doing this, Wagner shows how power and control of public space is determined at local, regional and State levels to the detriment of the individual.

The papers in this special issue focus on the nature and function of legal concepts, such as Transparency, Control and Power, but they do so in very different contexts, thus illustrating the overwhelming importance of such concepts in the present-day socio-political, economical, institutional and other public domains.

\section{Reference}

1. Scollon, Ron. 1998. Mediated discourse as social interaction: A study of news discourse. New York: Longman. 